\title{
A SUPERPOSIÇÃO DE ESPELHOS NA RETÓRICA DE VIEIRA
}

Marli de Oliveira Fantini Scarpelli

Universidade Federal de Minas Gerais

O espelho é o instrumento de uma universal magia que transforma coisas em espetáculos, espetáculos em coisas, eu no outro, o outro em mim.

(Merleau-Ponty)

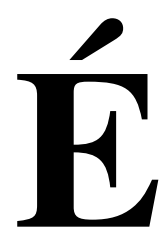

de tal forma recorrente o uso do "olhar" e do "espelho" na extensa e variada obra do Padre António Vieira, que os reflexos dessas imagens acabam por refletir seu criador. O instigante estudo da obra vieiriana feito por Saraiva e Lopes aponta para uma relação não convencional, mas antes substancial entre a palavra e a coisa significada na linguagem desse sermonista. Os dois estudiosos sugerem que, tais como ocorrem na obra de Vieira, a frase e as palavras deveriam ser interpretadas como invólucros de essências misteriosas. Isso suposto, desenvolvem a premissa de que, para exprimir essas essências, Vieira recorreria a processos que, pretendendo-se rigorosamente lógicos, seriam, na realidade, etimológicos. ${ }^{1}$

É inegável que esse pressuposto essencialista pode ser identificado na obra em questão - o que provoca, aliás, o impulso de abrir parênteses para problemas de gênese e de fratura identitária desse vulto diaspórico, meio estrangeiro por onde quer que transite. Não pretendendo, no entanto, perder de vista que a abordagem

${ }^{1}$ SARAIVA, António José; LOPES, Óscar. Padre António Vieira. História da Literatura Portuguesa. Lisboa. p.512-3. 
ontológica das palavras ou a utilização de suas possibilidades etimológicas representam, muitas vezes - não só para o sermonista, mas para outros pregadores ou escritores barrocos - um recurso retórico, "um fingimento deveras", experimentar-se-á, neste ensaio, uma outra abordagem.

Talvez mais do que todos seus seguidores e muitos de seus biógrafos, o embaixador-catequista sabia que, para converter gregos a troianos; burlar inquisição e aliciar judeus; pactuar com Deus e contemporalizar com o Diabo, era preciso saber representar. A manifestação do desgaste provocado pelos inúmeros ofícios e disfarces do jesuíta desenha-se numa carta em que este, dirigindose a um sacerdote, deixa vazar o jogo autoria/atoria, verdade/ verossimilhança, revelador da mescla entre vida e obra. Nessa carta, entre desencantado e lúcido, ele explicita as regras do próprio jogo. Desvestido do papel que se via quase invariavelmente obrigado a representar, um Vieira epistolar, quase inteiramente outro, explicita, entre lúcido e desencantado, as regras do próprio jogo. "Não há maior comédia que a minha vida; e quando quero chorar ou rir, ou admirar ou dar graças a Deus ou zombar do mundo, não tenho mais que olhar para mim (...)".2

Importa frisar que, no plano das estratégias dramático-verbais vieirianas, o recurso à repetição de um universo de referências cognoscíveis é uma estratégia de recursividade, o que, dessa forma, não pode esgotar-se apenas sob a perspectiva da linguagem. Quando, por exemplo, através da releitura das parábolas bíblicas, Vieira chama a atenção para a realidade encenada em seus próprios sermões, ele está, na verdade, deslocando o olhar do expectador para um novo contexto, para uma finalidade e uma práxis que não estavam inscritos no texto primeiro. Isso pode ser verificado, dentre outros, no "Sermão da Sexagésima". Neste, o aparente "xadrez de

${ }^{2}$ VIEIRA, António. "Carta a um padre". Fevereiro de 1658. Apud: PIMENTA, Carlos; ROQUE, Jorge.

${ }^{3}$ VIEIRA, António. "Sermão da Sexagésima". Obras completas do Padre António Vieira: Sermões. p.4. 
palavras", que provoca o deslizamento de "paço" para "passos", não é tão-somente um preciosismo cultista, mas um extemporâneo deslizamento do significante, a partir de cuja percepção, o sermonista espera fazer erodir a "fé abstrata" ou a "razão pura" para, então, convertê-las em ação, em práxis. Assim, a forma e a finalidade, mediante as quais Vieira utiliza, neste sermão, a "Parábola do Bom Semeador", garantem primeiro a descontextualização da alegoria bíblica, para, em seguida, operar-se sua ressemantização e sua conseqüente adaptação ao contexto nada santo das disputas verbais e temporais entre jesuítas e dominicanos. Mas a grande questão implicada nesse deslocamento é sobretudo o convite a uma nova mirada histórica. A expectativa é a de que se abandone o "dentro" em favor de um "fora". Sair de dentro para empreender novas passadas provoca a ampliação dos limites topográficos e, como resultado, o deslocamento do foco. Afinal, é conhecido o fato de que implodir velhos paradigmas fazia parte dos planos salvíficos do missionário. É assim que, filosoficamente embasada na "razão prática", a "ação" - um dos mais fortes e recorrentes sustentáculos da arquitetura vieiriana - vai contribuir para as conecções de seu sólido edifício alegórico, cuja construção, ainda que labiríntica e recursivamente desdobrável, acaba por privilegiar o tempo em detrimento do espaço, ampliando-se, portanto, mais para o futuro do que para o alto.

Agora se trata de estabelecer a homologia entre a emperrada máquina do "Antigo Estado" e o cenário imperialista de um Reino em decadência político-econômica. Essa perspectiva obriga o olhar a um novo enfoque: deslocar-se do "interior" para o "exterior" representaria, malgrado os riscos, a saída política para Portugal. No moderno entendimento de Vieira, a não ser que esta nação estivesse amparada pelos novos paradigmas implicados no pensamento mercantilista, não estaria preparada para assumir novas perspectivas históricas e um papel mais atuante no mundo de trocas mercantis, condições, mediante cuja efetivação, as quimeras sebastianistas do Quinto Império - uma das crenças que embasam a argumentação vieiriana - poderiam tornar-se realidade. 
Para além de questões etimológicas, filosóficas ou políticas implicadas na magnificente teatralidade da retórica de Vieira, é ainda importante ressaltar que os meios - na intenção e na forma como estão implicados no discurso deste poderoso convertedor conformam-se a uma complexa e enredante estrutura sintática, cuja ossatura lógica torna verossímeis as criativas e ardilosas intrusões do juízo pessoal do sujeito do conhecimento. Ademais, ao sustentar com o concurso uma rede sintática entrecruzante e aliciadora - seu inverossímil visionarismo profético e seus especiosos silogismos, o orador se garante de meios suficientes para capturar seu receptor virtual e provocar-lhe mudanças estruturantes, dentre as quais aquelas circunscritas ao domínio das mais convictas crenças pessoais. Trata-se de uma estrutura que, ao repetir - sob novo enfoque - as perspectivas internalizadas, acaba por gerar novas conecções, podendo estas, por sua vez, atuar na produção de novos sistemas, num arranjo em que até mesmo as finalidades podem ser alteradas. É assim que os discursos vieirianos asseveram a convergência entre as crenças do convertedor e as daquele a quem se busca converter. ${ }^{4}$

Desde que investido de finalidades consideradas justas e necessárias, o retorcimento dos meios utilizados pelo diplomata do

${ }^{4}$ Quando trata dos recursos usados numa argumentação, que se queira assumir como verdade demonstrada, e, portanto, capaz da persuasão, Perelman e Olbrets-Tyteca chamam a atenção para a necessidade de "convergência", uma espécie de concordância entre o orador e seu ouvinte. Segundo os ensaístas, o argumento corre o risco de se tornar inaceitável, caso seja incompatível com as expectativas ou as crenças do interlocutor. Caso isso ocorra, torna-se necessário estabelecer um novo tipo de "convergência". Nas palavras dos dois estudiosos, "isso nos leva a salientar um novo tipo de convergência. É aquela que se pode constatar entre um conjunto conhecido, crença religiosa, sistema científico ou filosófico, e um argumento que o vem confirmar: fato novo que corrobora um sistema científico, interpretação de um texto particular que corrobora um sistema jurídico, uma concepção de valores". In: PERELMAN, Chaim; OLBRECHTS-TYTECA, Lucie. Tratado da argumentação: a nova retórica. p.536. 
Rei e de Deus torna-se justificado e eticamente válido. Isso ocorre sobretudo naquelas situações em que o sermonista necessita ser inventivo o bastante para garantir a eficácia de seus argumentos.

No sermão do "Demónio mudo", por exemplo, Vieira descreve a imagem terrificante e bem pouco ortodoxa de um Demónio, contra cuja influência, ele alerta as religiosas de Odivelas. Percebendo que as novidades acrescentadas ao tema causam espanto, o pregador dá o golpe de mestre: "Ninguém se benza, porque esta verdade, posto que seja fé católica, é romana. É a novidade que de lá trago, para que vos peço nova atenção". 5

A visibilidade é outro forte recurso dos discursos vieirianos. O que se quer demonstrar nos seus sermões deve ser, não apenas ouvido, mas visto. A plasticidade dá ao abstrato a garantia do concreto. Assim, se as imagens de "visão" e "espelho" têm presença iluminada no texto vieiriano, também a sintaxe, à medida que nela se enredam vários recursos e várias vozes dialógicas, resulta em efeitos especulares e espetaculares: ecos, gradações, reiterações, recursividade. Espelhamento entre a visão e o corpo sintático que a sustenta.

\section{Narciso só acha feio o que não é espelho}

O Vieira metafísico bem sabe que não se pode fiar no entendimento decorrente da percepção sensorial. É indubitável sua adesão à crença platônica, e esta o alerta para os riscos da falsificação do real - os enganos, a distorção, o instantaneísmo da percepção, obtidos sem a mediação da razão e do entendimento. Ainda assim, ao Vieira pregador e missionário, torna-se-lhe imperativo convocar a visão, o olhar, os olhos, de cujo concurso ele necessita para dar materialidade e concreção ao imaterial.

5VIEIRA, António. "Demónio mudo". Obras completas do Padre António Vieira: Sermões. p.319. 
No metassermão "da Sexagésima", ele explica quais procedimentos devem ser experimentados pelos espectadores da prédica, para assegurar que o ouvido se transforme em visto; e o visto, em exemplo de ação a ser emulada: "as palavras ouvem-se, as obras vêem-se; as palavras entram pelos ouvidos, as obras entram pelos olhos, e a nossa alma rende-se muito mais pelos olhos que pelos ouvidos" 6 .

Visando a essa mesma finalidade, o sermonista cita um pregador que, tendo descrito verbalmente a "Paixão de Cristo" - não obstante ter feito corresponder uma imagem plástica a cada detalhe pungente que vinha sendo enumerado - só logrou mobilizar a emoção e a adesão apaixonada dos espectadores, depois de apresentar, com o concurso de reiterações enfáticas, a imagem concreta do Ecce Homo. Depois de expor o milagre provocado pela visibilidade, Vieira o retoma em seu próprio discurso, no qual irá, especularmente, reproduzir o espetáculo que acabara de referir. A expectativa é a de que - capturado pelo mise-en-abyme- o espectador se torne, não só assistente, mas, enquanto co-ator e co-autor, também agente transformador da realidade alegorizada na cena.

Corre-se neste passo uma cortina, aparece a imagem do Ecce Homo; eis todos prostrados por terra, eis todos a bater no peito, eis as lágrimas, eis os gritos, eis os alaridos, eis as bofetadas. Que é isto? Que apareceu de novo nesta igreja? Tudo o que descobriu aquela cortina, tinha já dito o pregador. Já tinha dito daquela púrpura, já tinha dito daquela coroa e daqueles espinhos, já tinha dito daquele cetro e daquela cana. Pois se isto então não fez abalo nenhum, como faz agora tanto? - Porque então era Ecce Homo ouvido, e agora é Ecce Homo visto; a relação do pregador entra pelos olhos. Sabem, Padres pregadores, por que fazem pouco abalo os nossos sermões? - Porque não pregamos aos olhos, pregamos só aos ouvidos. ${ }^{7}$

${ }^{6}$ VIEIRA, António. "Sermão da Sexagésima”. Sermões. p.127-8.

${ }^{7}$ Op. cit., p.128-9. 


\section{Mercantilismo providencial}

Sacerdote, catequista da Companhia de Jesus, evangelizador, abolicionista extemporâneo, pregador com extraordinários dotes literários, Vieira - ancorado por uma estratégia política que certamente ultrapassava as habilidades possíveis de sua cultura, sobretudo no que diz respeito ao trânsito entre as diferenças - foi também um arguto negociador. Quando ensina que "A verdadeira fidalguia é a ação", esse lutador contumaz demonstra que quem possui comprovada habilidade no manejo de palavras e espelhos, pode ter também manejar outras armas. Gregório de Matos, contemporâneo de Vieira, mantém com este algumas semelhanças temáticas e estruturais no trato da palavra, como o engaño e o desengaño, o tensionamento religioso, a teatralidade, o uso das analogias, a evidentia barroca, o contorcimento retórico. O pregador guarda, entretanto, uma diferença fundamental em relação ao poeta, já que tem os olhos voltados para o futuro, para o empreendimento e para as mudanças. Enquanto a poética daquele se desdobra, entre melancólica e irônica, para responsabilizar a "máquina mercante" pelo declínio e agonia do "Antigo Estado", Vieira, diferentemente, - sobretudo quando encarnado na figura do embaixador político do Reino - em lugar de nostalgia, põe as mãos à obra, investindo sua máquina retórica, não contra, mas a favor da máquina mercante. ${ }^{8}$

No século XVII, muitas das mudanças econômicas já estabelecidas em Estados mercantilistas, como Holanda e Inglaterra, eram uma necessidade do mundo moderno. Vieira sabia disso, e seu afã político de salvar o Estado português do declínio econômico leva-o à arriscada empresa de carrear seus pares para a nova ordem européia.

${ }^{8}$ A idéia de comparar Vieira a Gregório de Matos adveio da leitura e dos inúmeros dados de que me vali com a leitura de dois ensaios de Bosi. In: BOSI, Alfredo. Do Antigo Estado à máquina mercante e Vieira ou a cruz da desigualdade. Dialética da colonizaçâo. 
Revestido pelo então monarca, d. João IV, do duplo encargo de "pregador régio" e "embaixador político", Vieira propõe empregar o capital judeu na reconstrução do Estado empobrecido pelas Guerras da Restauração. A negociação seria feita com base numa permuta muito mais proveitosa aos portugueses que aos judeus, então deportados, pela máquina do Santo Ofício. A estes, acenava-se com a isenção do confisco de seus bens - vantagem imediata e temporal - mas não de todo convincente. A mediata e providencial é sustentada pela tese visionária da consolidação, em Portugal, do "Quinto Império do mundo", o maior império da cristandade. Este sonho messiânico, orientado pela bula profética do Sebastianismo, é, segundo Alcir Pécora, a "parte essencial da argumentação de Vieira" na defesa de sua tese política, pois o que ele tenta basicamente provar é que "apenas a este Estado estava destinado um papel compatível com o futuro previsto pela crença judaica" - o ressurgimento do Messias e a recondução desses povos diaspóricos à própria pátria. Este é indubitavelmente um procedimento recorrente no discurso de Vieira: trata-se do concurso de meios que se desdobram e se contorcem para construir a argumentação e para justificar os planos salvíficos deste conselheiro de reis e papas. Um exemplo disso se encontra no "Sermão de S. Roque" em que se fala da validade dos diferentes meios com que, estando Elias perdido no deserto, tem saciada sua fome: duma feita, por anjos; doutra, por corvos.

Tão Deus era Deus quando sustentava a Elias por ministério de corvos, como quando o sustentava por ministério de anjos: e tão santo era Elias quando recebia o pão das mãos dos anjos, como quando tomava o pão das unhas dos corvos. E a razão disto qual é? A razão é, porque a bondade das obras está nos fins, não nos instrumentos. As obras de Deus são todas boas; os instrumentos de que se serve, podem ser bons e maus. ${ }^{10}$

${ }^{9}$ Cf. PÉCORA, Alcir. A exegese do capital.

${ }^{10}$ VIEIRA, António. "Sermão de S. Roque”. p. 80. 
Corporificação de inextrincáveis tensões, a enunciação vieiriana acaba por representar, na diversificada e provocante obra do pregador, o palco onde infindáveis e labirínticos jogos de espelhos tentam dar conta das máscaras e ofícios por meio dos quais o jesuíta-embaixador perambula pelo deslizante espaço de Metrópole, Colônia e potências rivais, em meio à disputas pelo controle territorial, econômico e ideológico da Terra de Santa Cruz.

Multifacetado por inúmeros encargos - conselheiro de reis e confessor de rainhas, diplomata em cortes européias e defensor de cristãos-novos, adepto ferrenho do ideal colonizador de "dilatar a fé e o Império" - Vieira acaba por encarnar, em sua obra, o gran teatro del mundo, onde o jogo de autoria/atoria faz, reflexiva e simultaneamente, do sujeito o principal objeto enfocado.

O rebuscado uso de linguagem tropológica, de procedimentos analógicos, do recurso à imagerie e à especularidade labiríntica, de

${ }^{11}$ Penso que, se o próprio sujeito da enunciação alinha-se sincronicamente a tendências da contemporaneidade, não custa ressaltar também que a mirada filosófica e histórica de António Vieira segue a mesma vertente. A atualíssima História das mentalidades, vertente da Nova História, reconhece a necessidade do uso de recursos da tropolologia e da suplementar interferência interpretativa do sujeito do conhecimento, por cuja voz narrativa, "os acontecimentos passados" são atualizados no processo de enunciação. Em entrevista intitulada "O historiador, hoje", Georges Duby, afirma que (nós, historiadores) "fomos progressivamente descobrindo que a objetividade do conhecimento histórico é um mito, que toda a história é escrita por um homem e que quando esse homem é um bom historiador põe na sua escrita muito de si próprio" (p.9). Noutra passagem, ele exemplifica essa tendência, quando pergunta: "O que é um acontecimento? É qualquer coisa que só existe porque se fala dela” (p.15). Mas, fala-se, segundo ele, do que se deseja; e isso se faz sem se perder de vista que a "elaboração do material é sempre feita de uma forma subjetiva" (p.10). DUBY, Georges. O historiador, hoje. In: DUBY, G.; ARIES, P; LADURIE, E.L.R.; LE GOFF. Ver ainda, a esse respeito: NUNES, Benedito. Narrativa histórica e narrativa ficcional. In: RIEDEL, Dirce Côrtes (Org). 
citações bíblicas e filosóficas por este artesão da retórica tribunícia são - a par de sua contribuição ao Barroco culto, maneirista - instrumentos de que ele se vale para catequizar, exortar, converter, driblar inimigos, mobilizar Deus e exorcizar o Diabo. Mas, sobretudo, para atingir o que julga necessário às mudanças a que aspira. É assim que - (dis)torcida pela retórica da conversão - a verdade, no palco vieiriano, não é mais importante que a verossimilhança. ${ }^{11}$

Dois dentre os mais fortes recursos usados por Vieira são, como vimos, os olhos e o espelho. Se este, dependendo da necessidade de argumentação, pode ser a face narcísica do demónio, como no "Sermão do demónio mudo", doutra parte, o afã de mobilizar ninguém menos que Deus, no "Sermão pelo bom sucesso das armas de Portugal contra as de Holanda", infla o orador a utilizar, na cena deste sermão, um "espelho do mundo" onde, uma a uma, são chamadas a comparecer, com sua imagem, incontáveis vozes bíblicas, épicas e filosóficas para, com o concurso analógico e plástico, dar concretude visiva ao quadro para o qual espera sejam vertidos os olhos e a complacência divina.

\section{O Pharmakón de Vieira}

O espelho em Vieira ora é remédio, ora veneno. Ora meio, ora fim. Em algumas vezes, instrumento do demônio; em outras, de Deus. Antíteses, paradoxos nem sempre conseguem cobrir o vasto campo escópico cujo enfoque ora se alarga ora se refrata para abranger funções e intenções diversificadas e muitas vezes antagônicas entre si. É preciso forte empenho retórico, pois a empresa a que se propõe o "Embaixador do conjuntural e do providencial" ultrapassa os limites da capacidade humana. Para tanto, Vieira recorre ao jogo quiásmico e barroco do duplo espelhamento, de sorte a fazer caber, na sua sintaxe, a palavra e a imagem correspondente; a intenção e seus eufemismos; a etimologia com seus parentescos semânticos e sonoros; o assunto e sua alegorização; o olhar e seu duplo especular. João Adolfo Hansen 
identifica, na biblioteca de Coimbra, um folheto de 1733 - "Acto Especulativo e Prático" - o qual faz referência a um conceito científico sobre "luz". Este conceito, segundo o crítico, afina-se com a mesma forma paradoxal utilizada por Vieira para representar o olhar e o espelho.

Dado na forma de um conceito agudo a ser demonstrado - "Prova-se que a luz é coisa obscurantíssima" -, o pressuposto implica a definição da matéria luz, sensível e visível, como "sombra", porque emanação participada na substância metafísica de Deus, afinal a única Luz autêntica, mas obscurantíssima porque absolutamente perfeita para a intuição platonizante. Aparece na formulação, de novo, a articulação do quiasma típica da arte de Vieira: a luz sensível, visível, é totalmente obscura, porque a luz inteligível, invisível, é totalmente clara. ${ }^{12}$

\section{A cegueira na luz}

O tema cartesiano do malin génie é encenado - como um luciferino duplo divino encarnado no espelho - no "Sermão do Demônio mudo". Com este sermão, o pregador alerta e adverte as religiosas de Odivelas do perigo que encerra o "espelho", aí tratado como o lugar onde - pela intervenção do demônio, o "demônio mudo" - a realidade pode ser falsificada.

Exortadas a se livrarem do espelho demoníaco, as religiosas têm do pregador uma promessa de bonnaire, com a garantia de salvação - um outro espelho, o de Deus, mediante cuja contemplação, elas serão certamente beneficiadas, porque a Ele estarão especularmente identificadas.

É um espelho de tão diferente artifício, que olhando para ele, não nos vemos semelhantes a nós, mas ele só com a sua vista nos fará semelhantes a si. Isto é o que já nos referiu com autoridade de fé o gloriosíssimo pai desta sagrada comunidade, S. Bernardo: Similis ei

\footnotetext{
${ }^{12}$ HANSEN, João Adolfo. O profeta da luz. Caderno Mais! Folha de São Paulo. ${ }^{13}$ Idem, ibidem, p.351.
} 
erimus, quoniam videbimus eum sicut est: Seremos semelhantes a Deus, porque veremos a Deus como Ele é. Fiquem agora considerando os olhos mais cegos, se se deve deixar um espelho, que é Deus. ${ }^{13}$

\section{O esplender do concreto}

A evidentia barroca, a rede quiásmica de cruzamento e superposição de planos, o mise-en-abyme, a dramatização da fé cristã, a erudição, o jogo analógico, os recursos reiterativos e hiperbólicos, o apelo à imagerie, o perfeito domínio no manejo de silogismos e espelhos atinge o "esplendor do concreto" ${ }^{4}$, no Gran teatro del mundo encenado por Vieira, no "Sermão pelo bom sucesso das armas de Portugal contra as de Holanda".

Este é um sermão em que a simbiose entre alegoria bíblicocristã e pensamento mercantil, bem como a posição litigante de que se reveste o sermonista dão a ver as várias personas textuais de António Vieira. Nesta ameaçadora prédica, são aplicadas as "leis tridentinas" em um réu, que é ninguém menos que Deus. Imitando os procedimentos do Santo Ofício, o sermonista convoca o acusado a se defender da omissão e, portanto, do pecado cometido contra seu próprio corpo místico. E, desconsiderando hierarquias, irá convocar o réu à "ação", com a mesma sem cerimômia com que já aliciara seus próprios pares a essa empresa.

Nesse sermão, um grande espelho do mundo se entreabre às vistas do Senhor e, uma a uma, várias vozes bíblicas, que já contaram com o perdão divino, são trazidas à cena para fazê-lo lembrar-se de que, mesmo os que se mostraram indignos, foram agraciados por seu beneplácito. Se Deus não intervier favoravelmente ao português, ora ameaçado pela iniqüidade do herege holandês, se não agir com complacência e perdão, terá seu reino ameaçado, e a validade da fé que o sustenta estará em julgamento. Voltando dramaticamente

${ }^{14}$ A expressão é de Bosi. Op. cit., p 306. 
um espelho contra Deus, o diretor do espetáculo acaba trazendo à cena uma imagem invertida, onde o que se reflete é a face demoníaca do inimigo. É preciso interpelar Deus, denunciar a distorção do foco e reconduzi-lo à sua verdadeira imagem.

Que diga o herege (o que treme de o pronunciar a língua), que diga o herege, que Deus está holandês? Oh não permitais tal, Deus meu, não permitais tal, por quem sois. Não o digo por nós, que pouco ia em que nos castigásseis: não o digo pelo Brasil, que pouco ia em que o destruísseis; mas por Vós o digo e pela honra de vosso Santíssimo Nome, que tão imprudentemente se vê blasfemado: Propter nomen tuum. (...)

Um exasperado agente da empresa colonizadora convoca Deus à ação imediata: salvar o Brasil da invasão e dominação holandesa. Mas, na verdade, o que se erige nessa arquitetura barroca é uma sinuosidade quase escandalosa, visando a uma radical mudança de foco: o que se quer é a ampliação dos domínios espirituais e comerciais da Cristandade, em cuja esfera Vieira tão habilmente transita.

Então, o que importa não é a verdade, nem o acontecimento invocado ou mesmo a causa que o provocou. Como tudo isso é apenas um pretexto para se atingir uma dada finalidade, todos os meios utilizados - sejam eles sintáticos ou filosóficos, sejam a verdade ou seu fingimento - concorrem para intenção que o pregador tem em vista. É assim que, nesse contexto de demanda pela reformulação do olhar, a repetição de várias vozes bíblicas faz atualizar e ressignificar o sentido alegórico cristalizado pela tradição cristã. Para isso acontecer, é preciso usar um código cognoscível o da tradição incorporada -, mas com combinações tais que possibilitem a formação de outras condensações, outras séries imagéticas. A formação de metáforas a partir de signos como culpa, remorso, condenação, absolvição - buscados ao código inquisitorial combinados na seriação analógica com outros como troca, ganho, perda, prejuízo, compensações, barganha - apropriados ao código mercantilista - constitui o campo dinâmico das novas relações que se quer instituir. A recursividade obriga o velho, os antigos valores e as antigas combinações a permutar, de sorte a gerar nova alegoria, 
a qual traz implicada, em seu bojo, a nova organização que deve ser introjetada pelos fiéis.

O responsável pela enunciação do "Sermão do bom sucesso das armas de Portugal contra as de Holanda" é um padre, o Padre António Vieira. Trata-se de um sujeito do conhecimento que, valendo-se da prerrogativa do "padroado", sente-se no direito natural de cobrar de volta o Reino para cuja fundação ele investiu e para cuja manutenção ele teve de lutar com inúmeras armas, fossem elas as do embaixador, do catequisador ou do missionário. Se Portugal (com suas colônias) foi a nação escolhida pelo próprio Deus para a locação do "Quinto Império" - o futuro paraíso terreal -, por que entregar a mãos hereges esse reino onde se pretende a consolidação da fé católica no mundo?

$O$ arsenal bélico a ser montado tem de ser eficaz, pois tratase agora de manejar armas capazes de fazer frente ao herege holandês, que, não obstante representar uma ameaça concreta, irá, na verdade, metonimizar todo o novo contexto visado pelo sermão. Assim, o sermonista vai reutilizar, descontextualizando-os do seu sentido meramente cristão, os vários textos bíblicos que têm em comum a ira de Deus e sua posterior complacência. Ressalve-se, entretanto, que o diretor desta nova cena carrega deliberadamente nas tintas do remake feito aos atores do original bíblico, deformando-lhes grotesca e exageradamente a fisionomia, o que certamente causará estranhamento e mal-estar no espectador. No sermão de Vieira, o Senhor, traindo combinação anterior, pretere os portugueses, quando convida a participar, de seu banquete, luteranos e os calvinistas, que, além de mancos e cegos, são ainda hereges. Afinal, a idéia é trazer à cena fisionomias já vistas na parábola bíblica as quais, na série alegórica renovada, pelo sermão das "armas", aparecem dramaticamente alteradas, sob a forma da "monstruosa" face que dá imagem ao mal, à ameaça contra a qual se deve lutar.

Os cegos e mancos são os luteranos e calvinistas, cegos sem fé e mancos sem obras; na reprovação das quais consiste o principal erro de sua heresia. Pois se nós, que fomos os convidados, não nos escusamos, nem duvidamos de vir, antes rompemos por muitos inconvenientes, em que 
pudéramos duvidar: se viemos e nos assentamos à mesa, como nos excluís agora e lançais fora e introduzis violentamente os cegos e mancos, e dais os nossos lugares ao herege? ${ }^{15}$

Lado a lado com o grotesco traçado do inimigo, irrompem em meio a uma nada diplomática imprecação - margens para o ressentimento: "antes rompemos por muitos inconvenientes, em que pudéramos duvidar". Em que consistiria essa dúvida, e qual das inúmeras vozes desse espetáculo polifônico estaria fraturando o discurso? Surgiria dos bastidores uma outra voz, uma voz vieiriana em off, pondo em questão a validade da opção religiosa feita pelo porta-voz oficial da Igreja e pelos seus seguidores? Mesmo que não se possa afirmar com certeza a existência de uma ameaça real, não deixa, entretanto, de ser verossímil que todos esses bramidos não passem de encenação, de investimento em novos e insuspeitados meios de aliciamento.

A grande arena montada, no gran e labirintico teatro del mundo desse cenário textual, encena, entre outros, o duelo entre o "Novo" e a "Tradição". De um lado, o imobilismo crítico, conceitual e moral do "Antigo Estado". De outro, a modernidade da "máquina mercantil”, cujas novas engrenagens, Vieira demonstra conhecer na ponta da língua. Essa habilidade se desenha numa sintaxe de cruzamentos quiámicos e analogias enredantes, matizadas por metáforas de permuta, não somente simbólica, mas em conversação com o comércio emergente. Entrelaçada com o pragmatismo da nova ordem mercantil, esta é uma rede que concorre para o descondicionamento da visão, cujo foco quer-se agora invertido ou convertido para uma outra mirada histórica: a práxis, o trânsito e a fluidez espacial, a volaticidade da ética e da moral "antigas".

A mistura de negócios espirituais com os comerciais evidencia as "armas" de que fala metaforicamente o título deste sermão. São elas que Portugal precisa aprender a manejar em sua luta contra o "herege holandês", inimigo providencialmente datado por uma feliz

${ }^{15}$ Idem, p. 313. 
coincidência histórica. O poderoso recurso metonímico utilizado n'"O bom sucesso das armas de Portugal contra as da Holanda" põe os convertidos em guarda contra quaisquer facções que representem uma efetiva ou uma imaginária ameaça ao projeto português de "dilatar a Fé e o Império". Mobiliza-os, ademais, à nova ordem que se quer assimilada.

Se verdadeiro, isso confirmaria nosso pressuposto de que a especularidade em Vieira - ultrapassando a amplitude etimológica para a qual apontam os sentidos de specio-specto ${ }^{16}$ - é, não somente um artifício de conversão ou de validação do poder católico, mas um dos mais poderosos recursos de transformação dos paradigmas de fé em questões de Estado. De cristandade em mercantilidade.

Eis Vieira: um "eu" demasiadamente barroco, desdobrado em várias vozes dialógicas e reversíveis. Malgrado os múltiplos ofícios e máscaras vieirianos, pelo menos uma certeza: seja o Vieira imbuído de fé e mobilizado por uma missão, seja o Vieira "conselheiro do Estado absoluto", seja o "conselheiro do príncipe-mercador"17, seja Vieira ou Vieiras, a ele não se pode subtrair o mérito de, enquanto homem de seu tempo, ter sido capaz de provocar uma nova visada histórica. E enquanto escritor, de contribuir para o engenho e o esplendor da Literatura, qualidades que lhe tornam inquestionável o título de "Imperador da Língua Portuguesa".

${ }^{16}$ Marilena Chauí, em um ensaio sobre o "olhar", faz este levantamento etimológico sobre o assunto: "A gama de sentidos de specio-specto é de amplidão insperada: spectabilis é o visível; specimen, a prova, o indício, o argumento e o exemplo. Speculum (espelho) é parente de spetaculum (a festa pública) que se oferece ao spectator (o que vê, o espectador), que não apenas se vê no espelho e vê o espetáculo, mas ainda é capaz de voltar-se para o speculandus (a especular, a investigar, a examinar, a vigiar, a espiar) e de ficar em speculatio (sentinela, vigia, estar de observação, explorar, espreitar, pensar vendo) por que exerce a spectio (a vista, a inspeção pelos olhos, a leitura dos agouros) e é capaz de discernir entre as species e o espectrum (espectro, fantasma, aparição, visão irreal). CHAUÍ, Marilena. Janela da alma, espelho do mundo. In: NOVAES, Adauto. O olhar. p.36.

${ }^{17}$ A expressão assinalada é de BOSI. In: Op. cit., p.123. 


\section{Referências Bibliográficas}

BAÊTA NEVES, Luiz Felipe. Palavra, mito e história no Sermão dos sermões do Padre António Vieira. In: RIEDEL, Dirce Côrtes (Org.). Narrativa; ficção e história.Rio de janeiro: Imago, 1988.

BOSI, Alfredo. Do Antigo Estado à máquina mercante e Vieira ou a cruz da desigualdade. Dialética da colonização. São Paulo: Companhia das letras, 1994.

CHAUÍ, Marilena. Janela da alma, espelho do mundo. In: NOVAES, Adauto (Org.). O olhar. São Paulo: Companhia das letras, 1995.

HANSEN, João Adolfo. O profeta da luz. Caderno Mais! Folha de São Paulo. São Paulo: 13 de julho de 1997.

MERLEAU-PONTY, Maurice. O visível e o invisível. Trad. José Artur Gianotti e Armando Mora d'Oliveira. São Paulo: Perspectiva, 1992.

NUNES, Benedito. Narrativa histórica e narrativa ficcional. In: RIEDEL, Dirce Côrtes (Org.). Narrativa; ficção e história. Rio de janeiro: Imago, 1988.

PÉCORA, Alcir Bernárdez. O demónio mudo. In: NOVAIS, Adauto (Org.). O olhar. São Paulo: Companhia das letras, 1995.

PÉCORA, Alcir Bernárdez.. A exegese do capital. Caderno Mais! Folha de São Paulo. São Paulo: 13 de julho de 1997.

PERELMAN, Chaim; OLBRECHTS-TYTECA, Lucie. Tratado da argumentação: a nova retórica. Trad. Maria E. G. G. Pereira. São Paulo: Martins Fontes, 1996.

PESSANHA, J. A. História e ficção: o sono e a vigília. In: RIEDEL, Dirce Côrtes (Org.). Narrativa: ficção e história. Rio de Janeiro: Imago, 1988.

SARAIVA, António José; LOPES, Óscar. Padre António Vieira. História da Literatura Portuguesa. Lisboa: Porto editora, 1965.

VIEIRA, António. "Carta a um padre". Fevereiro de 1658. Apud: PIMENTA, Carlos; ROQUE, Jorge (seleção de textos de Vieira para o espetáculo: Vieira: a voz visível). Uma produção da Comissão Nacional para os Descobrimentos Portugueses. 
VIEIRA, António. "Demónio mudo". Obras completas do Padre António Vieira: Sermões. Porto: Lello \& irmãos editores, 1959. V.III.

VIEIRA, António. "Sermão da Sexagésima". Obras completas do Padre António Vieira: Sermões. Porto: Lello \& irmãos editores, 1959. V. I, p.Tomo I.

VIEIRA, António. "Sermão da Sexagésima". Sermões. Rio de Janeiro: Agir, 1985.

VIEIRA, António. "Sermão de S. Roque". Obras completas do Padre António Vieira: Sermões. Porto: Lello \& irmãos, 1959. V.III, tomo VIII.

VIEIRA, António. "Sermão pelo bom sucesso das armas de Portugal contra as de Holanda". Obras completas do Padre António Vieira. Porto: Lello \& irmãos editores, 1959.

\section{Resumo}

Corporificação de inextricáveis tensões, Vieira representa em sua diversificada e provocante obra - um "gran teatro del mundo", em cujo cenário, infindáveis e labirínticos jogos de espelhos tentam dar conta das máscaras e ofícios por meio dos quais o jesuíta perambula pelo deslizante espaço de Metrópole, Colônia e potências rivais. No ensaio que aqui se resumirá, pretende-se discutir, a partir da leitura do Sermão do "Diabo mudo" e do "Sermão pelo bom sucesso das armas de Portugal contra as de Holanda", dentre outros, a posição litigante em que se acham aí encenadas as várias personas textuais de Padre António Vieira.

\section{Résumé}

Dans ce "gran teatro del mondo", qui est l'oeuvre de Vieira, diversifiée et provocatrice, des jeux mirditantes et labyrinthiques essaient de s'emparer des masques et des fonections par les moyens desquels le jésuite chemine au milieu du glissant espace de la Métropole, de la Colonie et des pays rivals. Dans cet essay, on veut mettre en question, à partir de la lecture du Sermão do Diabo mudo et du Sermão pelo bom sucesso das armas de Portugal contra as de Holanda, parmi d'autres, le litige mis-en-scène par les personas textuelles du Padre António Vieira. 